\title{
The Use of Data-Driven Dialogue to teach English
}

\section{Muhammad Farhan Oniel}

Universitas Islam Indonesia, Indonesia

Email Correspondence: 15322040@ students.uii.ac.id

\begin{abstract}
The term data-driven data-driven dialogue (DDD) has emerged recently as a valuable tool for organizing classroom discussion of any predicted lessons and monitoring students' learning process in the classroo O'Brian, Nocon, and Sands (2010). The background of this study is most of the teachers in Indonesia tend to skip the dialogue process when they teach grammar to their students. These conditions impact the use of inappropriate grammar and decreased student interest in learning grammar, especially in English. Thus, this study aims to describe how data-driven dialogue methods can be applied in English classes for Senior High School students. The research was conducted in one of the Senior High Schools in Yogyakarta. The data collected through the DDD method using the four steps include (1) Predict, (2) Explore, (3) Explain, and (4) Take Action.
\end{abstract}

Keywords: data-driven dialogue method; teaching grammar; classroom management

\begin{tabular}{|l|l|l|}
\hline DOI & $:$ & https://doi.org/10.24903/bej.v3i1.708 \\
\hline Received & $:$ & January 2021 \\
\hline Accepted & $:$ & January 2021 \\
\hline Published & $:$ & February 2021 \\
\hline $\begin{array}{l}\text { Copyright and } \\
\text { License }\end{array}$ & $\begin{array}{l}\text { Authors retain copyright and grant the journal the right of first publication with } \\
\text { the work simultaneously licensed under a Creative Commons Attribution 4.0 }\end{array}$ \\
\hline $\begin{array}{ll}\text { International License that allows others to share the work with an acknowledgment of } \\
\text { the work's authorship and initial publication in this journal. }\end{array}$ \\
\hline
\end{tabular}




\section{INTRODUCTION}

Grammar teaching has been found to improve students' proficiency. Many scholars have developed and tested an array of teaching techniques that can best enhance students' grammar learning. However, surveys have repeatedly shown that grammar teaching in the classroom is still traditional in the sense that it is focused on structural pattern drilling and memorizing. This has been observed by Bjork (2005) assuming this long tradition of teacher-centered teaching and rote learning is often used in the Indonesian classroom. One reason for this persistence is that teachers often base their teaching practices on their experience as learners. Another reason might be that the techniques are not suitable for the aim of the lesson and/or the classroom situation. Several cases were found, not a few of the English teachers in Indonesia only asked their students to work on grammar questions based on the LKS (student worksheets) provided by the government, without ensuring that students understood or did not understand the grammar concept requested. Drilling has made students bored, students tend to rely on their memories without understanding the structure of grammar. The lack of explanation given by the teacher makes most students not interested in learning English.

Grammar is part of the English knowledge that must be mastered by teachers when teaching English. This is necessary to avoid misconceptions made by students in using grammar. Teachers can explain questions that arise and gain student trust during the learning process. However, the teacher only focuses on the teaching guide when teaching, explaining grammar structure without involving students in the process of understanding the grammar structure. These conditions have an impact on the use of inappropriate grammar and decreased student interest in learning grammar, especially English. Based on my observation during my internship program, most of the teachers tend to skip the dialogue process when they teach grammar to their students. Worksheets were given to students, they worked on it, and the teacher shared the correct answer. Even if the teachers explain the logic of correct grammar, yet the students tend to be uninvolved. They were set to be passive and raise questions only if they did not understand. Rarely did the teacher let the students explain their answers and explore resources to solve grammar problems. Thus, to fill this practical gap, This based practice aims to describe how data-driven dialogue can be applied in English classes for Senior High School students.

The term data-driven in this part means that term describes a process that educators collaboratively inquire about the meaning of data with other educators (Wellman and 
Lipton, 2004). A statewide teacher professional development institution, the Colorado Consortium for Data-Driven Decisions (C2D3), elaborated with Wellman and Lipton (2004) to describe a four-step process through which teams of educators co-construct meaning from data. Following the institute, these educators began to adapt data-driven dialogue as a tool for their students in the formative assessment during the teachinglearning process. Formative assessment as conceptualized by Carless (2008) is a type of assessment that is included during learning activities, such as to assess students' understanding, assess students' participation, or assess students' collaborative work. In this best practice, I did data-driven dialogue to assess my students' understanding of their grammar exercises. If I skipped data-driven dialogue, my students tend to just write the correct answer without performing a sufficient understanding of the grammar materials. Thus, data-driven dialogue has emerged recently as a useful tool for organizing classroom discussion of any predicted lessons as well as monitoring students' learning process in the classroom O'Brian, Nocon, and Sands (2010). The four steps include: Predict, Explore, Explain, and Take Action.

The First step is Predict, describe and identify materials that students expect to learn. In the classroom process, before they see the materials, students can make predictions about specific 'learning goals'. The second step is Explore, analyze materials, determine priorities, and create visual displays to support the materials. Students can identify the structure of the materials and make related examples based on the teacher's description. The third is Explain, interpret the materials, develop and validate theories with other materials sources. Students can describe the overall lesson and handle their misunderstanding about the materials directly. The last step is Take action, develop solutions based on identifying problems, and gather appropriate sources to control students' understanding of the materials. Students can find and solve their misunderstanding by themselves and take action for it.

Through this C2D3 research, the author tried to apply the steps to students in the K13 classroom context. Data-driven dialogue has been used by authors to co-construct English lesson instruction depending on students' level using formal assessment results to improve learning outcomes.

In the previous research, Black and Wiliam (1998) identified five specific practices that support formative assessment, for which they found substantial evidence of 
improvements in student learning outcomes. These included: (1) teachers sharing the criteria for evaluating learning with their students; (2) teachers using descriptive (as opposed to evaluative) feedback; (3) students self-assessing; (4) student-to-student peer assessing; and, (5) using questioning in classrooms to learn about learning. These six practices identified can be characterized as a student engaged, because each engages the student in gathering, analyzing/interpreting, and/or acting on/using information about his/her learning.

\section{METHODOLOGY}

This study applied a self-observational study, adapted from the DDD instructional design as constructed by O'Brian, Nocon, and Sands (2010). This paper aims to describe how data-driven dialogue can be applied in English classes for Senior High School students. The qualitative data was collected by the author to observe a teaching experience as primary data.

\subsection{Setting and Participants}

The setting of this study was conducted in one of the Senior High Schools in Yogyakarta. The school is located in Sleman, Yogyakarta, Indonesia. 32 students participated. Student's reflection study can be used as a parameter of students' comprehension in the classroom.

\subsection{Data Collection}

The information was gathered through student assignments and activities. The DDD method was used to analyze interactions and student engagements. First, the teacher starts the class by teaching the Simple Present Tense, then the teacher gives the students exercises and guides them through the process of creating 8 groups consisting of 4 members. The next step is for the student to seek information about the material in the textbook and LKS. Following that, students were instructed to complete the exercise and provide feedback on their findings. The final step is for students to reflect on what they have learned so far, what they still don't understand, and what steps they need to take to solve the problem. 


\subsection{Self-observational Study}

The author used self-observational studies to learn about a student's English level and to understand students' behavior during the learning process.

\subsection{Research Procedure and Data Analysis}

In this study, the author used the DDD method, which was based on O'Brian, Nocon, and Sands (2010).

Table 1 Data-driven Dialogue Procedure

\begin{tabular}{ll}
\hline Steps & Activity \\
\hline Predict, & Students describe and identify, make predictions about specific 'learning goals' \\
\hline Explore & Students analyze and make statements about the evidence related to 'learning goals' \\
\hline Explain & Students interpret the data and validate theories with other data sources. \\
\hline Take Action & Students develop and gather appropriate data to support action in solving problems.
\end{tabular}

\section{FINDINGS}

\subsection{Teacher Reflection}

The author already knows the average ability of students in English lessons before using the DDD method. The application of the DDD method requires students with higher-order thinking skills. Teachers should be prepared to assist students in reaching their learning objectives.

\subsection{Students Reaction}

The author claims that this method is well delivered and that students' interest in learning English has increased, it is proven by students' curiosity and willingness to ask questions, even after class has ended.

\section{DISCUSSION}

\subsection{Teaching Preparation}

When I arranged the questions on the worksheet, I paid attention to the student's English level and modified the form of the questions to make them easily understood by the students. Marked some questions that students may ask and prepared an explanation for these questions. 


\subsubsection{Exploring possible resources to answer the questions}

To enhance the resources in this material, I did not only refer to textbooks. I also searched at several websites to understand this material, enhance vocabularies, and gain question samples that I can use as references in making exercises.

Picture 1. The Reference of Teaching Materials from ESL Lab

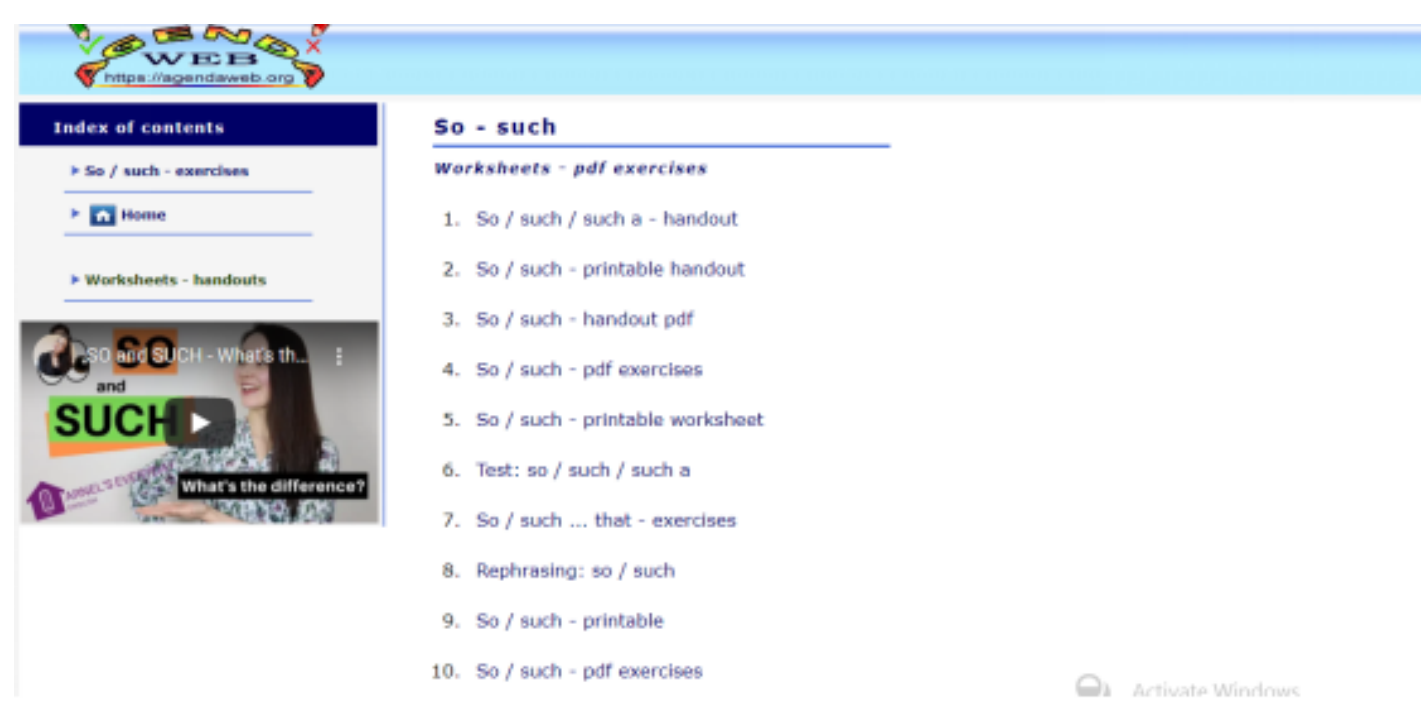

Picture 2. The Reference of Teaching Material From BBC World Service

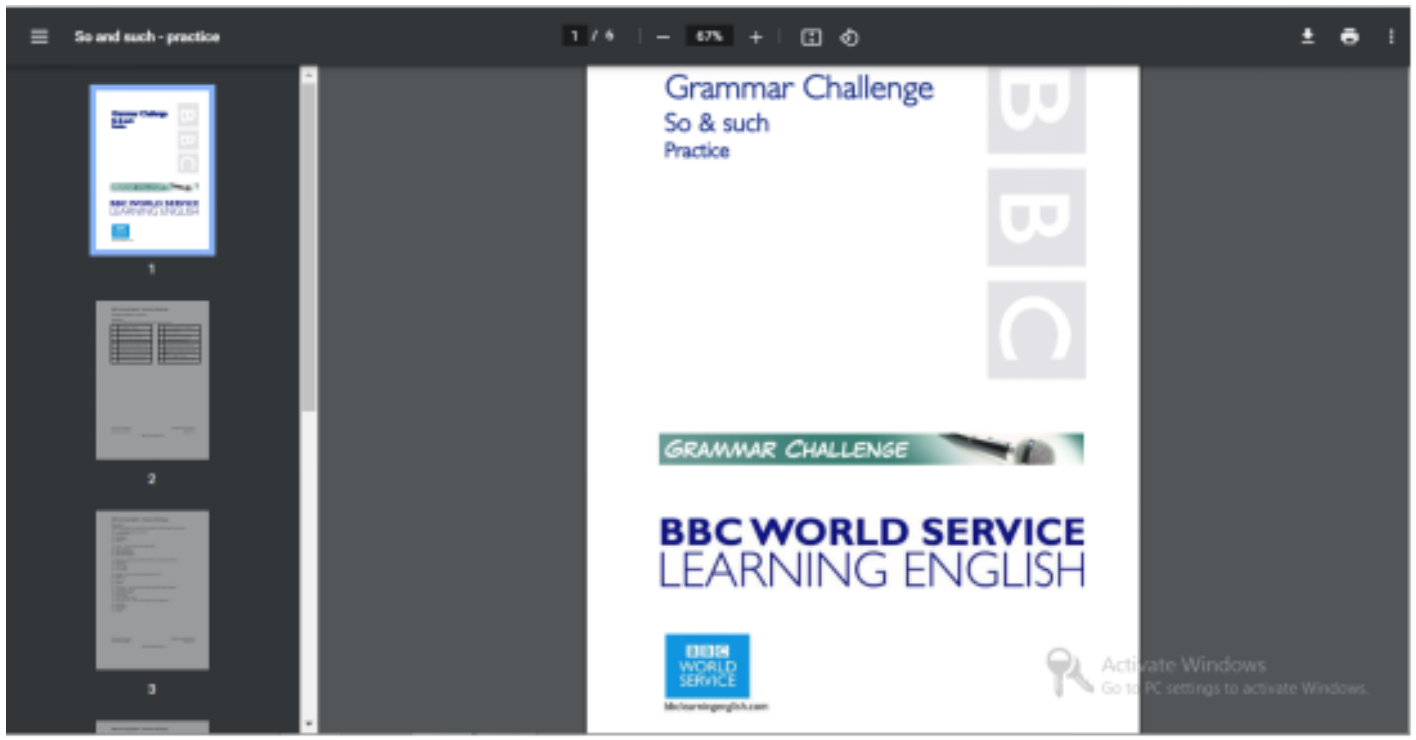

\subsubsection{Consulting the reference to the Teacher Supervisor}

The consultation was conducted in the school one time during the afternoon break. He suggested simplifying the material, providing a familiar example and exercise for students that follow the English students' level. 


\subsubsection{Adapting the Teaching Materials}

Those were the sources I used in creating materials and exercises. Those sources were enhanced by reference in modifying the exercise. I took the keywords from the explanation of the material, underlined, took notes, organized, and simplified this material according to the student's English level.

\subsubsection{Re consulting the Design of Teaching Materials to the Teacher Supervisor}

After the teaching preparation was complete, I handed over the Lesson Plan material to the teacher supervisor. He said that the Lesson Plan made is already good and can be used to teach. He suggested adding videos or images to capture students' attention while teaching.

\subsubsection{Finishing the Design}

In completing the design, I looked for an educational video related to the material, redesigning the lesson plan arrangement correctly.

\subsection{Teaching Practices}

\subsubsection{Pre-Activities: Explaining the Material to My Students}

As elicitation, I explain the Simple Present Tense formula to my students, because this tense is related to the material that I would deliver. I also added some examples to make them understand. I tested their understanding by writing 3 types of sentences: positive, negative, and interrogative sentences on the board. After that, I then asked a few students to modify forms of sentences into three types of sentences. The picture below shows how I presented the exercises:

Picture 3. The Exercise of Teaching Material

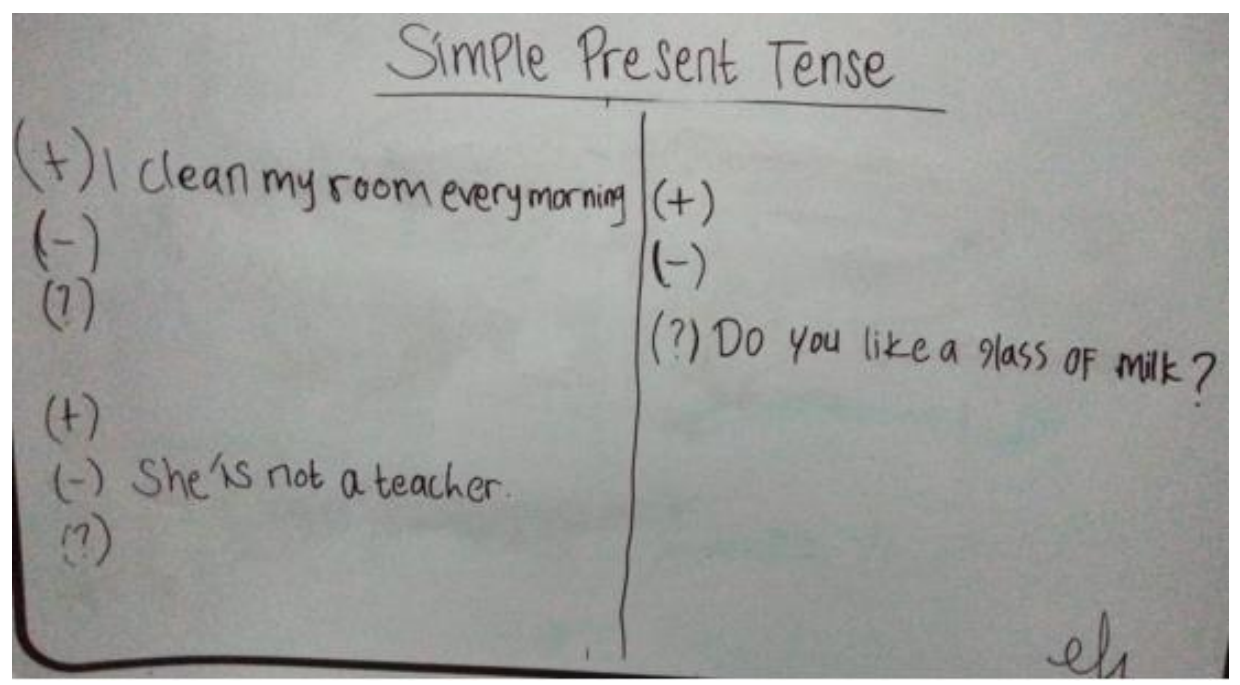


Based on this practice, almost all students in class understand how to modify forms of the simple present tense, they are familiar and can follow the lesson well. Errors such as grammar errors and miswriting can be resolved by reviewing their answers together. In delivering the material, I used a teaching aid, which was PowerPoint. The explanation of the material consists of two parts; Patterns and Functions. Inputting notes that I have made into PowerPoint, paying attention to the visual form of the material, and looking for relevant examples.

Picture 4. The Pattern of Material
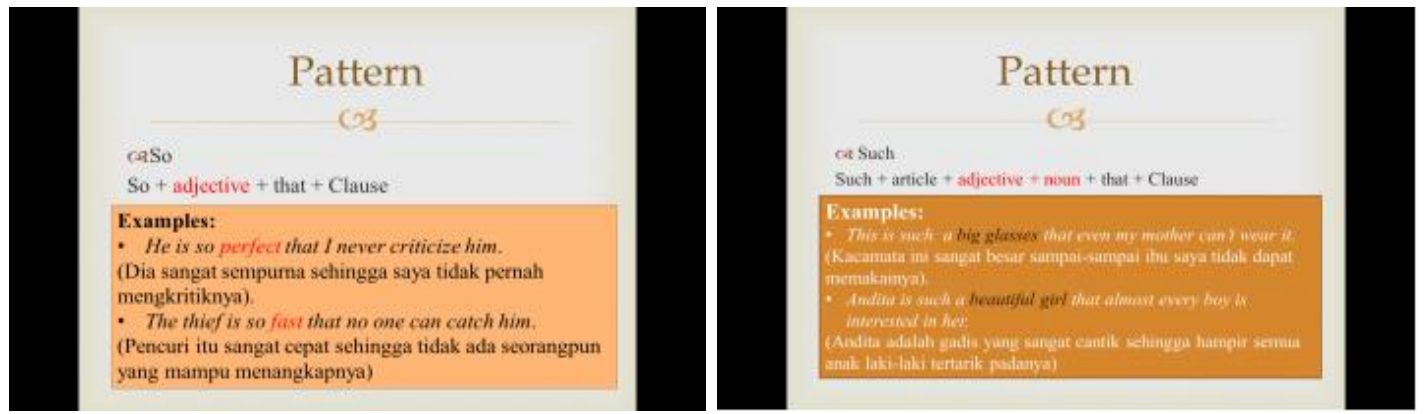

\subsubsection{Grammar Pattern}

The next step is to explain the Pattern. When explaining I ask students to pay attention to the type of words used, tell them the difference between Adjective and Noun in a sentence, to explain the structure of the sentence when this grammar is used. After that, I appointed some students to spontaneously make examples when using this grammar, a trial error that occurred made the other students pay attention to the explanation I gave.

Picture 5. The Function of Material

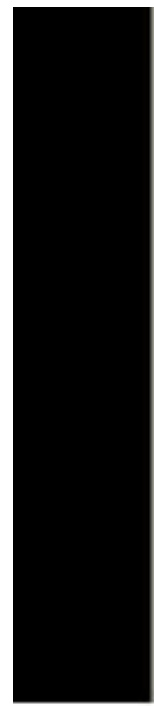

\section{Functions}

\section{$\cos$}

- To show a fact with the result or consequence,

Examples:

- It was so windy that we couldn't go sailing

- It's st - To show your extreme feeling or opinions about sever something

Examples:

He was so bed that he ask money to everyone here

- You are such a good person that you want to help each others.

\subsubsection{Grammar Functions}


I explained a little about the function of grammar as a complement to this material, making them more focused on learning goals. While explaining. I try to involve students in understanding this material. I asked how much they understood the information I provided by asking a few students to read and understand the examples that had been given. When explaining, a small discussion occurred, some of them asked questions and didn't understand the use of this grammar. I tried to explain the details and emphasize the points that must be considered when this grammar is used.

\subsection{While Activities (Data-Driven Stage 1: Predicting the answers of grammar exercises)}

I gave this activity after I had finished explaining the material. This exercise aimed to remind students of the material that was presented and introduced the use of this grammar to students. In this activity, the worksheets were distributed to all students, after that I asked them to categorize the differences between this two grammar, this activity was carried out in a group of four. They were asked to answer exercises that had been shared with their group mates. The students were allowed to ask questions and discuss with other group members. The purpose of this exercise is to get them used to write and train their sensitivity in recognizing forms of grammatical patterns as well as the functions.

Picture 6. The Exercise of Teaching Material

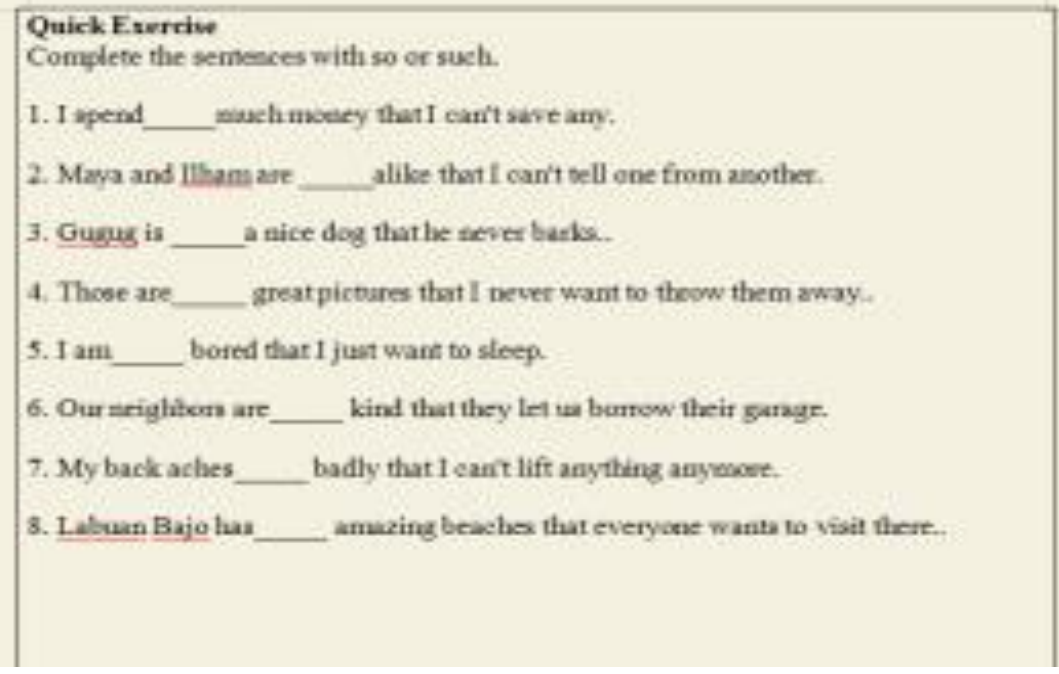


Picture 7. The Exercise of Teaching Material

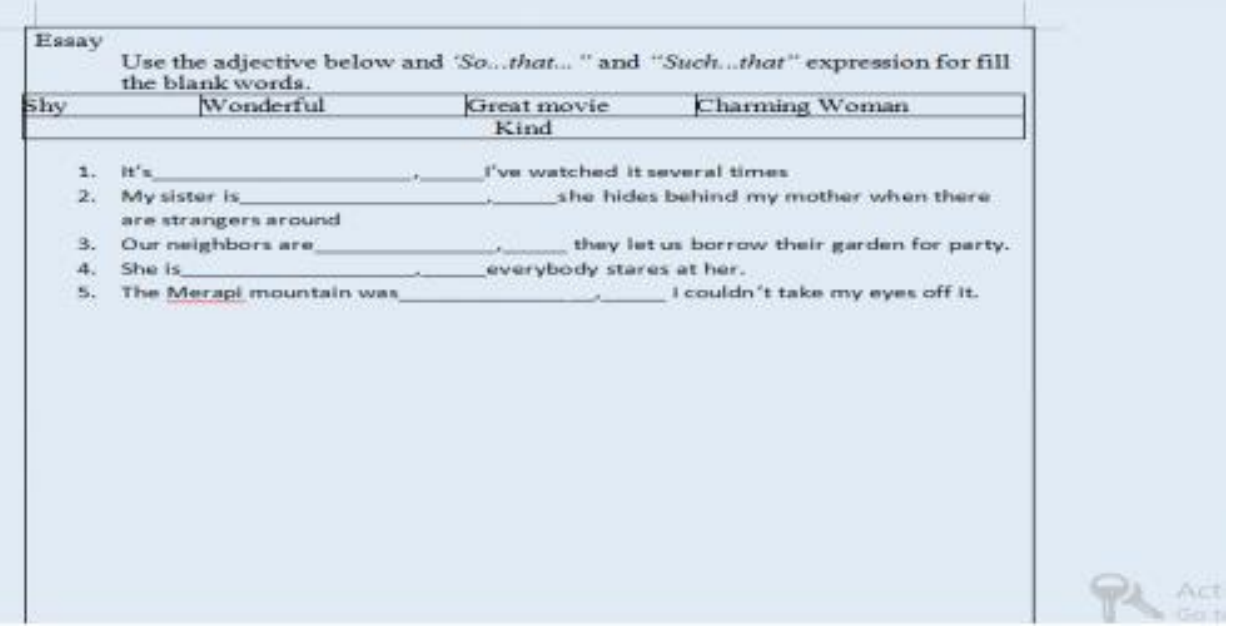

4.4 While Activity (Data-Driven Stage 2: Explore Possible Resources to Answer the Questions)

Because the school provides package books and LKS for students, the exploration of material refers to the book. In delivering this material, I made a rule not to allow students to use electronic devices in the classroom. This I do to avoid misuse of mobile phones used to open social media and play games.

\subsection{While Activity (Data-Driven Stage 3: Explain the Answer to the Teacher and other} Students)

I asked one of the students to answer and asked her the reason, then asked the other students whether the answer was correct. I gave a compliment when they were right, while wrong, I asked them to re-read the question and asked them to correct the mistakes they had made. In this way, I can predict their understanding and gain their trust while teaching. 
Picture 8. The Exercise of Teaching Material

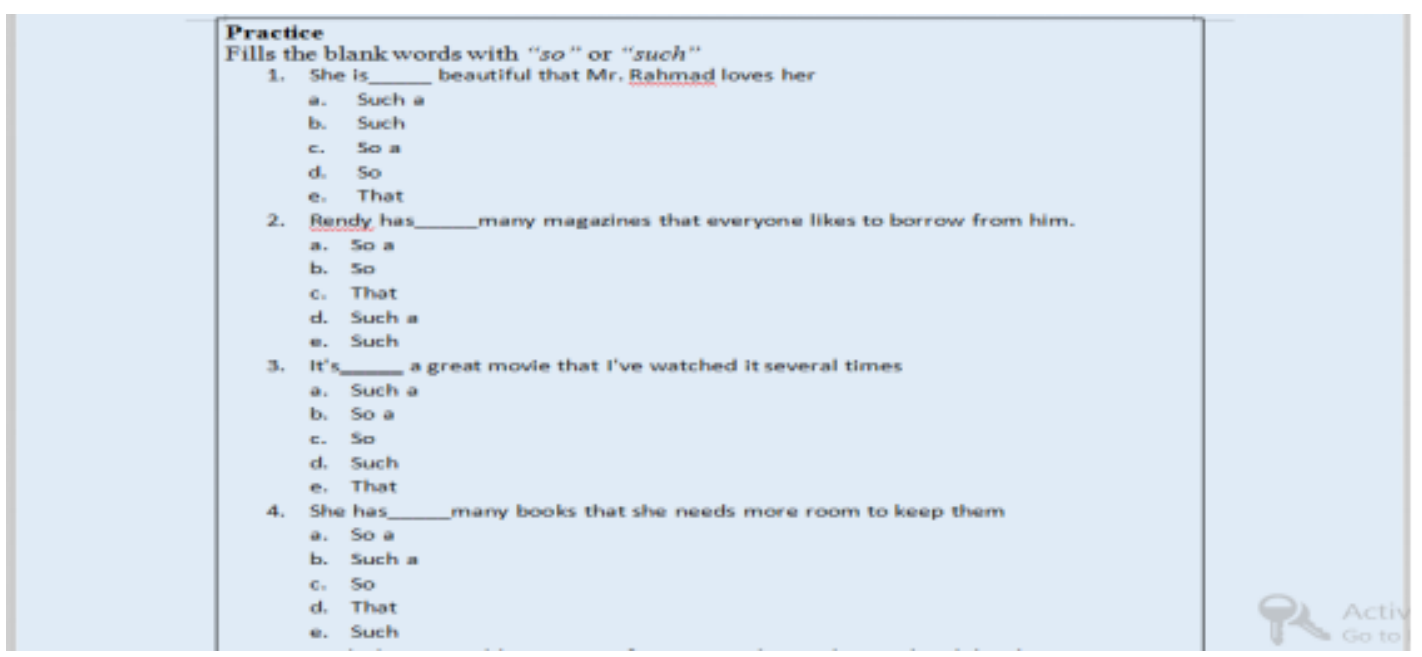

And the last activity is the multiple-choice exercise, in this activity, students were asked to work individually and were not allowed to discuss. There were 10 questions with a time of 15 minutes.

\subsection{Post Activity: (Data-Driven Stage 4) Reflection and Take Action to Solve the Problems}

Before closing the lesson, I asked them to write down what things they had learned, what things they had and didn't understand, and what suggestions they wanted to give me.

Picture 9. The Students' Reflection Study

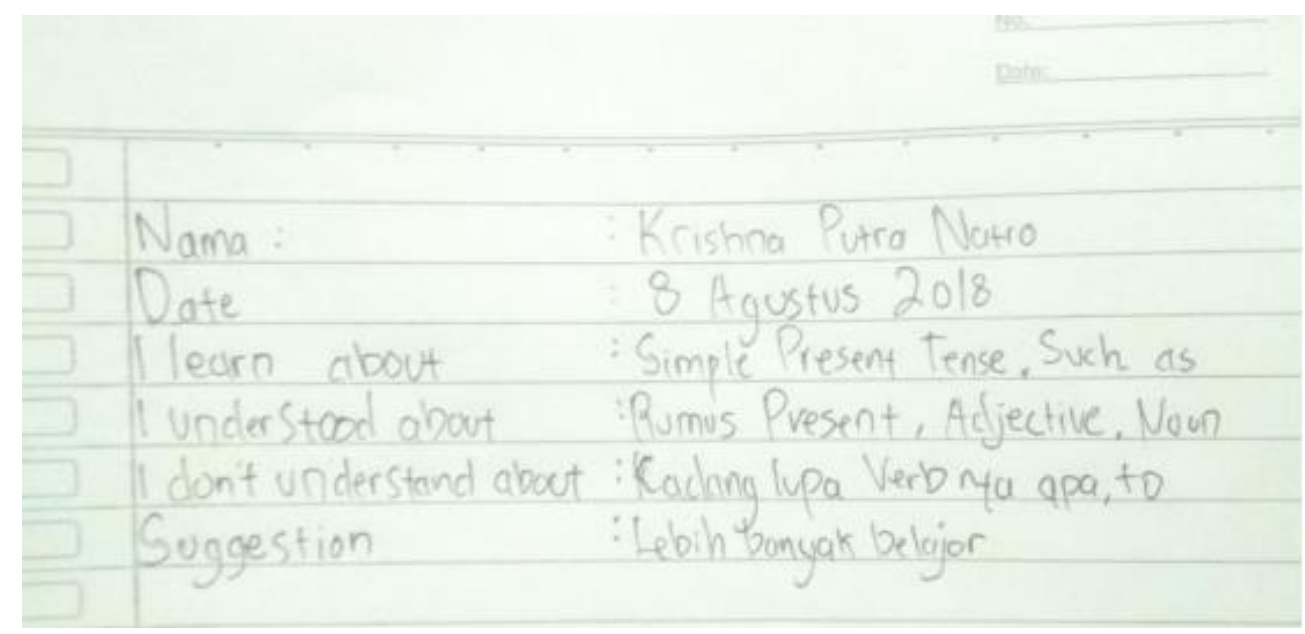

Here is an example of a table that I wrote on the board, I asked them to write on a piece of paper, then put it together. Based on the table, I can reflect on myself in teaching. Some students said that I was good enough at teaching (explaining and giving examples) but some said that I was still lacking in confidence and not yet firm. 
After the class was over, I was approached by several students. They asked several questions about the English lesson, some students said that they liked the way I taught compared to their teacher. He said, the explanation of the material given by the teacher was not clear enough and we were only asked to read the textbook and fill in the questions. I can conclude that interaction and brainstorming is the right way to learn English. They will find and share the information in their way, by itself making it easier for them to learn a lesson.

\section{CONCLUSION}

By conducting data-driven dialogue to teach English grammar to stimulate students' cognition, the students were more active and confident in solving their grammar exercises. It was proven by the willingness of some students to ask questions and argue about the material being taught, respond well to any questions given and encourage them to dare to try to use English in answering the exercises given.

However, there are some limitations to this method that must be considered. The method can only be used by students with an average intermediate to advanced level. According to the author, when using the DDD method, contextual teaching should be used: pre-activities, while-activities, and post-activities. According to O'Brian, Nocon, and Sands (2010), the procedure is not split and modified. The author also argues that the right time to implement this method is while until post activities because high-low students' engagement and students' interest, greatly influence the success of this method.

\section{REFERENCES}

[1] B. Wellman, and L. Lipton. "Data-driven dialogue: A facilitator's guide to collaborative inquiry," 2004.

[2] C. Bjork. "Indonesian Education: Teachers, Schools, and Central Bureaucracy," 2005.

[3] D. Carless. "Developing Productive Synergies between Formative and Summative Assessment Processes'. In M-F Hui and DL Grossman (eds)," Improving Teacher Education through Action Research, 2008.

[4] J. O. O'Brian, H. Nocon, D. I. Sands. "The use of dialogue and tools to develop students' mathematical language and meta-cognition," Teacher Development, vol.14:4 pp. 447-446, Dec 2010. 
[5] P. Black, and D. William. "Assessment and classroom learning," Assessment in Education, vol. 1 pp. 7-74, 1998. 